\title{
Predictors of 1-year mortality in patients on prolonged mechanical ventilation after surgery in intensive care unit: a multicenter, retrospective cohort study
}

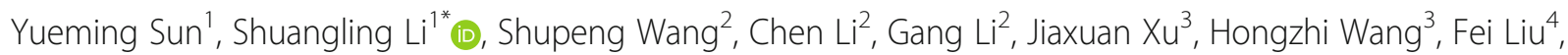
Gaiqi Yao ${ }^{4}$, Zhigang Chang ${ }^{5}$, Yalin Liư ${ }^{5}$ Meixia Shang ${ }^{6}$ and Dongxin Wang ${ }^{1}$

\begin{abstract}
Objectives: The requirement of prolonged mechanical ventilation (PMV) is associated with increased medical care demand and expenses, high early and long-term mortality, and worse life quality. However, no study has assessed the prognostic factors associated with 1-year mortality among PMV patients, not less than 21 days after surgery. This study analyzed the predictors of 1-year mortality in patients requiring PMV in intensive care units (ICUs) after surgery.

Methods: In this multicenter, respective cohort study, 124 patients who required PMV after surgery in the ICUs of five tertiary hospitals in Beijing between January 2007 and June 2016 were enrolled. The primary outcome was the duration of survival within 1 year. Predictors of 1 -year mortality were identified with a multivariable Cox proportional hazard model. The predictive effect of the ProVent score was also validated.

Results: Of the 124 patients enrolled, the cumulative 1-year mortality was 74.2\% (92/124). From the multivariable Cox proportional hazard analysis, cancer diagnosis (hazard ratio [HR] 2.14, 95\% confidence interval [Cl] 1.37-3.35; $P<0.01$ ), no tracheostomy (HR 2.01, 95\% Cl 1.22-3.30; $P<0.01$ ), enteral nutrition intolerance (HR 1.88, 95\% Cl 1.192.97; $P=0.01)$, blood platelet count $\leq 150 \times 10^{9} / \mathrm{L}(\mathrm{HR} 1.77,95 \% \mathrm{Cl} 1.14-2.75 ; P=0.01)$, requirement of vasopressors ( $\mathrm{HR} 1.78,95 \% \mathrm{Cl} 1.13-2.80 ; P=0.02)$, and renal replacement therapy (HR 1.71,95\% Cl 1.01-2.91; $P=0.047$ ) on the 21 st day of mechanical ventilation (MV) were associated with shortened 1-year survival.

Conclusions: For patients who required PMV after surgery, cancer diagnosis, no tracheostomy, enteral nutrition intolerance, blood platelet count $\leq 150 \times 10^{9} / \mathrm{L}$, vasopressor requirement, and renal replacement therapy on the $21 \mathrm{st}$ day of MV were associated with shortened 1-year survival. The prognosis in PMV patients in ICUs can facilitate the decision-making process of physicians and patients' family members on treatment schedule.
\end{abstract}

Keywords: Intensive care unit, Prolonged mechanical ventilation, Postoperative patients, 1-year mortality

\footnotetext{
*Correspondence: lishuangling888@hotmail.com

'Department of Critical Care Medicine, Peking University First Hospital,

Beijing 100034, China

Full list of author information is available at the end of the article
}

(C) The Author(s). 2020 Open Access This article is distributed under the terms of the Creative Commons Attribution 4.0 International License (http://creativecommons.org/licenses/by/4.0/), which permits unrestricted use, distribution, and reproduction in any medium, provided you give appropriate credit to the original author(s) and the source, provide a link to the Creative Commons license, and indicate if changes were made. The Creative Commons Public Domain Dedication waiver (http://creativecommons.org/publicdomain/zero/1.0/) applies to the data made available in this article, unless otherwise stated. 


\section{Introduction}

Mechanical ventilation (MV) is a frequently applied invasive technique to patients admitted in the intensive care unit (ICU). Although MV is usually seen as a lifesaving strategy, it has a strong potential to worsen the prognosis with prolonged use. According to the 2005 consensus of the National Association for Medical Direction of Respiratory Care (NAMDRC), prolonged mechanical ventilation (PMV) is defined as the requirement of MV for more than $6 \mathrm{~h}$ daily and that lasts for more than 21 consecutive days [1]. The requirement of PMV is associated with increased medical care demand and expenses [2,3], high early and long-term mortality $[4,5]$, and worse life quality [6-9]. Therefore, it is necessary to evaluate the prognosis in PMV patients in ICUs to facilitate the decision making process of the physicians and patients' family members on treatment schedule in the ICUs.

In 2008, Carson and colleagues [10] developed a mortality-prediction model (Prognosis for Prolonged Ventilation, i.e., ProVent score) to estimate the risk of 1 -year mortality in patients receiving MV for at least 21 days. They used four factors including age, platelet count, use of vasopressors, and requirement of renal replacement therapy to calculate the ProVent score. Another study showed only low platelet count on the 21st day of MV as a predictor of 1-year mortality in patients requiring PMV in a medical ICU in Korea [11]. However, in a mixed ICU study in France, use of vasopressors, and requirement of renal replacement therapy are predictors of 1-year mortality in patients requiring PMV [12]. Therefore, due to the inconsistent findings, further studies are needed to evaluate this further. In addition, no study has yet to demonstrate the predictors of 1-year mortality in patients requiring PMV in ICU after surgery. The purpose of this study was to analyze the predictors of 1-year mortality in patients requiring PMV in ICU after surgery.

\section{Material and methods}

This was a multicenter, retrospective cohort study.

\section{Ethics approval and consent to participate}

The study protocol was approved by the Ethics Committee of Peking University First Hospital (2017[1422]). As the study was purely observational and retrospective in nature, the Ethics Committee agreed to exempt the written informed consent. However, all enrolled patients or their family members had to verbally agree to participate in the longterm follow-up before the data collection.

\section{Patients}

Patients who required MV after surgery in the ICUs in five tertiary hospitals (Peking University First Hospital, Peking University Third Hospital, China-Japan Friendship Hospital, Beijing Cancer Hospital, and Beijing Hospital) in Beijing between January 2007 and June 2016 were screened. The inclusion criteria were those aged 18 years or older, admitted to the ICU after surgery, and received MV for at least 21 consecutive days. Patients who met any of the following criteria were excluded: acute or chronic neuromuscular diseases (such as Guillain-Barré syndrome, muscular dystrophy, amyotrophic lateral sclerosis, or myasthenia gravis), requirement of invasive MV before ICU admission, or incomplete clinical information.

\section{Patient and public involvement}

The research question and outcome were not informed by patients' priorities, experience, and preference. $\mathrm{Pa}$ tients didn't involve in the design of this study. Patients didn't involve in the recruitment to and conduct of the study. The results wasn't disseminated to study participants. All enrolled patients or their family members verbally agree to participate in the long-term follow-up before the data collection and researchers thanked them.

\section{Clinical data collection}

Data were collected using the medical record system in each hospital. Baseline data included demographic characteristics (age and gender), preoperative comorbidities, the New York Heart Association (NYHA) functional classification, liver and renal function tests, radio- or chemotherapy within 6 months, reason for surgery, location of surgery. Others included the scores of Sequential Organ Failure Assessment (SOFA) [13] and Acute Physiology and Chronic Health Evaluation (APACHE) II within the first $24 \mathrm{~h}$ after ICU admission.

On the 21st day of MV, data including platelet count, requirement of renal replacement therapy (currently or within $48 \mathrm{~h}$ ), use of vasopressors (currently or within 48 h), mode of nutritional supplementation, state of consciousness, presence of multi-drug resistant bacterial infection, and performance of tracheostomy were collected. Other data including the duration of MV, length of stay in ICU and hospital, and ICU and hospital mortalities, were recorded. The 3-month, 6-month, and 1-year survival status after day 21 of MV were documented from the medical record system or at follow-up. The record was checked every three months.

\section{Statistical analysis}

Patients were divided into survivor and non-survivor groups according to the 1-year survival status. 
Continuous variables were presented as means \pm standard deviation (SD) or median (interquartile range [IQR]) and compared with unpaired t test or Mann-Whitney $U$ test. Categorical variables were presented as numbers (\%) and compared using $X^{2}$ or Fisher's exact test. The 95\% confidence interval $(\mathrm{CI})$ of mortality in patients was estimated by the Bootstrap method (the number of execution samples was 1000).

Factors in association with 1-year survival were analyzed using the Cox proportional hazard model. Factors with number of events $>10$ were screened. Ten factors were identified at univariate analysis. Those with $P<$ 0.10 were included in the multivariate model after testing for collinearity. Collinearity of factors were tested using linear regression. Independent factors in association with 1-year survival were identified using a backward stepwise method. The effects of the combination of our multivariate factors and the ProVent score in predicting 1-year survival in patients with PMV were compared using the receiver operator characteristic (ROC) curves and the area under the curve (AUC). All tests were two-sided. $P$ values $\leq 0.05$ were considered statistically significant. Statistical analysis was performed with the SPSS 21.0 software package (Inc, Chicago, IL).

\section{Results}

\section{Patient recruitment and baseline characteristics}

From January 2007 to June 2016, 33,131 patients who were admitted to ICUs in the 5 tertiary hospitals were screened for study participation. Of these, 156 patients (0.5\%) required PMV after surgery (incidence of PMV was $0.5 \%)$; and $124(0.4 \%)$ fulfilled the inclusion/ exclusion criteria and were included in the final statistical analysis (Fig. 1).

Of 124 patients included in the study, mean $( \pm$ SD) age was $66.5( \pm 16.5)$ years, $72.6 \%(90 / 124)$ were male, and $35.5 \%$ (44/124) underwent cancer surgery (Table 1).

\section{Status on day 21 of mechanical ventilation}

Compared with 1-year non-survivors, those who survived underwent more tracheostomy $(P<0.01)$ and enteral nutrition $(P=0.01)$, suffered less from low platelet-count $\left(\leq 150 \times 10^{9} / \mathrm{L} ; P=0.02\right)$, and required less renal replacement therapy $(P=0.03)$ (Table 2).

\section{Outcomes}

Of all included patients, when counted from the 21st day of MV, the median duration of MV was 35 days (interquartile range [IQR] 27-61). The median length of stay in ICU and hospital were 44.0 (IQR 31.3-73.5) and 65.5 (IQR, 41.3-117.3) days, respectively. The mortality rates were $67.7 \%$ [84/124] (95\% confidence interval [CI] 59.7-75.8\%) in ICU, 71.0\% [88/124] (95\% CI 62.979.0\%) in hospital, and 74.2\% [92/124] (95\% CI 66.9$81.5 \%)$ at 1 year. The main cause of death was multiple organ failure syndrome (MODS) induced by septic shock $(67.0 \%[59 / 124])$.

\section{Factors associated with 1-year survival}

Factors with number of events $>10$ were screened. Ten factors were identified at univariate analysis $(P<0.10)$ (Table 3).

Of these, SOFA score was excluded because of collinearity with APACHE II score. The remaining nine

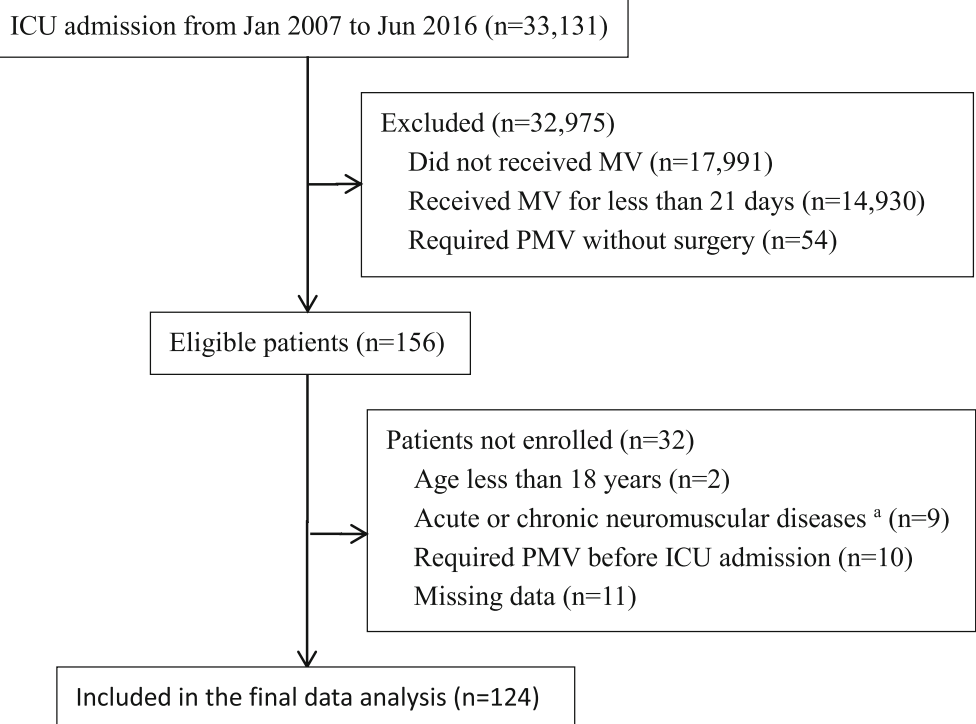

Fig. 1 Flow chart of the study. ICU, intensive care unit. MV, mechanical ventilation. PMV, prolonged mechanical ventilation. ${ }^{\text {In }}$ (n)luded GuillainBarré syndrome, muscular dystrophy, amyotrophic lateral sclerosis and myasthenia gravis 
Table 1 Baseline characteristics

\begin{tabular}{|c|c|c|c|c|}
\hline & $\begin{array}{l}\text { Total } \\
(N=124)\end{array}$ & $\begin{array}{l}\text { Non-survivors } \\
(N=92)\end{array}$ & $\begin{array}{l}\text { Survivors } \\
(N=32)\end{array}$ & $P$ value \\
\hline Age (y) & $66.5 \pm 16.5$ & $67.8 \pm 15.8$ & $62.8 \pm 18.1$ & 0.138 \\
\hline Male sex & $90(72.6)$ & $67(72.8)$ & $23(71.9)$ & 0.917 \\
\hline \multicolumn{5}{|l|}{ Preoperative comorbidities } \\
\hline Central nervous system & $24(19.4)$ & $19(20.7)$ & $5(15.6)$ & 0.535 \\
\hline Stroke & $16(12.9)$ & $13(14.1)$ & $3(9.4)$ & 0.760 \\
\hline Cephalomeningitis & $5(4.0)$ & $3(3.3)$ & $2(6.3)$ & 0.603 \\
\hline Parkinsonism & $2(1.6)$ & $2(2.2)$ & $0(0.0)$ & $>0.999$ \\
\hline Intracranial aneurysm & $1(0.8)$ & $1(1.1)$ & $0(0.0)$ & $>0.999$ \\
\hline Dementia & $1(0.8)$ & $1(1.1)$ & $0(0.0)$ & $>0.999$ \\
\hline Respiratory system & $37(29.8)$ & $27(29.4)$ & $10(31.3)$ & 0.839 \\
\hline Smoking ${ }^{a}$ & $31(25.0)$ & $22(23.9)$ & $9(28.1)$ & 0.636 \\
\hline Tuberculosis & $5(4.0)$ & $5(5.4)$ & $0(0.0)$ & 0.326 \\
\hline Asthma & $4(3.2)$ & $3(3.3)$ & $1(3.1)$ & $>0.999$ \\
\hline COPD & $4(3.2)$ & $2(2.2)$ & $2(6.3)$ & 0.274 \\
\hline Pulmonary heart disease & $1(0.8)$ & $1(1.1)$ & $0(0.0)$ & $>0.999$ \\
\hline Circulatory system & $79(63.7)$ & $59(64.1)$ & $20(62.5)$ & 0.869 \\
\hline Hypertension & $66(53.2)$ & $49(53.3)$ & $17(53.1)$ & 0.989 \\
\hline Coronary heart disease & $27(21.8)$ & $22(23.9)$ & $5(15.6)$ & 0.328 \\
\hline Arrhythmia & $14(11.3)$ & $8(8.7)$ & $6(18.8)$ & 0.122 \\
\hline Cardiomyopathy & $1(0.8)$ & $1(1.1)$ & $0(0.0)$ & $>0.999$ \\
\hline Metabolic and immune system & $35(28.2)$ & $30(32.6)$ & $5(15.7)$ & 0.066 \\
\hline Diabetes & $24(19.4)$ & $21(22.8)$ & $3(9.4)$ & 0.097 \\
\hline Hyperlipemia & $5(4.0)$ & $5(5.4)$ & $0(0.0)$ & 0.326 \\
\hline Thyroid disease & $2(1.6)$ & $2(2.2)$ & $0(0.0)$ & $>0.999$ \\
\hline Rheumatoid arthritis & $2(1.6)$ & $1(1.1)$ & $1(3.1)$ & 0.451 \\
\hline Gout & $1(0.8)$ & $1(1.1)$ & $0(0.0)$ & $>0.999$ \\
\hline Systemic lupus erythematosus & $1(0.8)$ & $0(0.0)$ & $1(3.1)$ & 0.258 \\
\hline NYHA functional classification & & & & 0.058 \\
\hline । & $63(50.8)$ & $42(45.7)$ & $21(65.6)$ & \\
\hline$\|$ & $34(27.4)$ & $30(32.6)$ & $4(12.5)$ & \\
\hline III & $17(13.7)$ & $11(12.0)$ & $6(18.8)$ & \\
\hline IV & $10(8.1)$ & $9(9.8)$ & $1(3.1)$ & \\
\hline Abnormal liver function ${ }^{b}$ & $5(4.0)$ & $4(4.4)$ & $1(3.1)$ & $>0.999$ \\
\hline Abnormal renal function ${ }^{c}$ & $5(4.0)$ & $4(4.4)$ & $1(3.1)$ & $>0.999$ \\
\hline Radio-/chemotherapy in 6 months & $4(3.2)$ & $2(2.2)$ & $2(6.3)$ & 0.274 \\
\hline Cancer surgery & $44(35.5)$ & $40(43.5)$ & $4(12.5)$ & 0.002 \\
\hline Location of surgery & & & & 0.015 \\
\hline Intra-thoracic & $45(36.3)$ & $39(42.4)$ & $6(18.8)$ & \\
\hline Intra-abdominal & $40(32.3)$ & $30(32.6)$ & $10(31.3)$ & \\
\hline Others $^{d}$ & $39(31.5)$ & $23(25.0)$ & $16(50.0)$ & \\
\hline Preoperative ASA classification & & & & 0.270 \\
\hline I & $10(8.1)$ & $9(9.8)$ & $1(3.1)$ & \\
\hline$\|$ & 63 (50.8) & $43(46.7)$ & $20(62.5)$ & \\
\hline
\end{tabular}


Table 1 Baseline characteristics (Continued)

\begin{tabular}{|c|c|c|c|c|}
\hline & $\begin{array}{l}\text { Total } \\
(N=124)\end{array}$ & $\begin{array}{l}\text { Non-survivors } \\
(N=92)\end{array}$ & $\begin{array}{l}\text { Survivors } \\
(N=32)\end{array}$ & $P$ value \\
\hline III & $22(17.7)$ & $16(17.4)$ & $6(18.8)$ & \\
\hline IV & $29(23.4)$ & $24(26.1)$ & $5(15.6)$ & \\
\hline Urgent surgery & $37(29.8)$ & $27(29.3)$ & $10(31.3)$ & 0.839 \\
\hline ICU admission for new onset POCs & $31(25.0)$ & $18(19.6)$ & $13(40.6)$ & 0.018 \\
\hline \multicolumn{5}{|l|}{ Scores on ICU admission } \\
\hline SOFA score & $7.4 \pm 3.3$ & $7.6 \pm 3.4$ & $6.5 \pm 2.5$ & 0.051 \\
\hline APACHE II score & $20.0 \pm 7.3$ & $20.9 \pm 7.7$ & $19 \pm 5.7$ & 0.210 \\
\hline
\end{tabular}

Results are presented as mean \pm SD and numbers (\%)

COPD, chronic obstructive pulmonary diseases. NYHA, the New York Heart Association. ICU, intensive care unit. POCs, postoperative complications. SOFA,

sequential organ failure assessment. APACHE, acute physiology and chronic health evaluation

${ }^{a}$ Smoking for more than 10 cigarettes per day for more than 1 year, including current or past smokers

${ }^{b}$ Serum alanine transaminase or aspartate transaminase higher than 5 times of the normal upper limit

'Defined as glomerular filtration rate (GFR) $<60 \mathrm{ml} / \mathrm{min} / 1.73 \mathrm{~m}^{2}$

${ }^{d}$ Include neurosurgery, thyroid surgery and orthopedic surgery

factors were included in the multivariate Cox proportional hazard model. Six independent factors were identified to be associated with 1-year survival. Cancer surgery (hazard ratio [HR] 2.14, CI 1.37-3.35; $P<0.01$ ), no tracheostomy (HR 2.01, 95\% CI 1.22-3.30; $P<0.01$ ), enteral nutrition intolerance (HR 1.88, 95\% CI 1.192.97; $P=0.01)$, platelet count $\leq 150 \times 10^{9} / \mathrm{L}(\mathrm{HR} 1.77$, 95\% CI 1.14-2.75; $\mathrm{P}=0.01)$, vasopressor requirement (HR 1.74, 95\% CI 1.11-2.74; $P=0.02$ ), and renal replacement therapy (HR 1.71, 95\% CI 1.01-2.91; $P=0.047$ ) on the 21st day of MV were associated with shortened 1year survival (Table 4).

\section{Comparison between the combination of our multivariate factors and the ProVent score in predicting 1-year mortality}

The combination of multivariate factors could be used in predicting 1-year survival in these patients with PMV after surgery (area under curve [AUC] 0.81 [95\% CI
0.72-0.89]). The ROC curve was based on the combination of all the 6 independent predictors of death.

There was significant difference between the combination of our multivariate factors and the ProVent score in predicting 1-year mortality in these patients with PMV after surgery (area under curve [AUC] 0.81 [95\% CI $0.72-0.89]$ vs. 0.69 [95\% CI $0.58-0.80] ; P<0.01$ ) (Fig. 2).

\section{Discussion}

Despite a small incidence of postoperative PMV of only $0.5 \%$, among patients, the mortality were as high as 67.7 and $71.0 \%$ in the ICU and hospital, respectively. In studies on patients with PMV in ICUs, the reported 1-year mortality varied from 48 to $67 \%$ [11, 12, 14], which is lower than that in our cohort (74.2\%). Patients on PMV after surgery had worse 1-year prognosis than patients in mixed and medical ICUs. From the China National Committee on Aging data (http://www.cncaprc.gov.cn/

Table 2 Patients' situation on the 21st day of mechanical ventilation

\begin{tabular}{|c|c|c|c|c|}
\hline Situation on 21st day of MV & $\begin{array}{l}\text { Total } \\
(N=124)\end{array}$ & $\begin{array}{l}\text { Non-survivors } \\
(N=92)\end{array}$ & $\begin{array}{l}\text { Survivors } \\
(N=32)\end{array}$ & $P$ value \\
\hline No tracheostomy & $31(25.0)$ & $30(32.6)$ & $1(3.1)$ & $<0.01$ \\
\hline Consciousness (GCS = 15) & $74(59.7)$ & $54(43.6)$ & $20(62.5)$ & 0.71 \\
\hline Drug-resistant bacteria infection & $63(50.8)$ & $51(55.4)$ & $12(37.5)$ & 0.08 \\
\hline MDR & $50(40.3)$ & $39(42.4)$ & $11(34.4)$ & 0.43 \\
\hline $\mathrm{XDR}$ & $13(10.5)$ & $12(13.0)$ & $1(3.1)$ & 0.18 \\
\hline Intolerance of enteral nutrition ${ }^{a}$ & $43(34.7)$ & $38(41.3)$ & $5(15.6)$ & 0.01 \\
\hline Platelet $\leq 150 \times 10^{9} / \mathrm{L}$ & $49(39.5)$ & $42(45.7)$ & $7(21.9)$ & 0.02 \\
\hline On vasopressors & $41(33.1)$ & $33(35.9)$ & $8(25.0)$ & 0.26 \\
\hline On renal replacement therapy & $24(19.4)$ & $22(23.9)$ & $2(6.3)$ & 0.03 \\
\hline
\end{tabular}

Results are presented as mean $\pm \mathrm{SD}$, median (interquartile range) and numbers (\%)

MV, mechanical ventilation. GCS, Glasgow coma scale. MDR, multi-drug-resistant. XDR, Extensively drug-resistant

${ }^{a}$ Included total parenteral and combined enteral-parenteral nutrition 
Table 3 Risk factors in association with 1-year survival (univariate Cox Proportional Hazard analyses)

\begin{tabular}{|c|c|c|c|}
\hline Risk factors & $\mathrm{N}$ & $\operatorname{HR}(95 \% \mathrm{Cl})^{a}$ & $P$ value \\
\hline \multicolumn{4}{|l|}{ Baseline characteristics } \\
\hline \multicolumn{4}{|l|}{ Age (y) } \\
\hline$<50$ & 20 & 1.000 & \\
\hline $50-64$ & 25 & $1.06(0.51-2.19)$ & 0.89 \\
\hline$\geq 65$ & 79 & $1.48(0.81-2.69)$ & 0.20 \\
\hline Male sex & 90 & $1.05(0.66-1.66)$ & 0.85 \\
\hline Stroke & 16 & $1.09(0.60-1.95)$ & 0.78 \\
\hline Smoking ${ }^{b}$ & 31 & $1.18(0.73-1.90)$ & 0.51 \\
\hline Hypertension & 66 & $1.09(0.72-1.64)$ & 0.69 \\
\hline Coronary heart disease & 27 & $0.87(0.54-1.40)$ & 0.56 \\
\hline \multicolumn{4}{|l|}{ NYHA functional classification } \\
\hline $\mid+\|$ & 97 & 1.000 & \\
\hline$I I I+I V$ & 27 & $1.01(0.62-1.66)$ & 0.97 \\
\hline Diabetes & 24 & $1.13(0.89-1.44)$ & 0.33 \\
\hline Cancer diagnosis & 44 & $1.20(0.98-1.48)$ & 0.08 \\
\hline \multicolumn{4}{|l|}{ Location of surgery } \\
\hline Others $^{c}$ & 39 & 1.000 & \\
\hline Intra-thoracic/abdominal & 85 & $1.73(1.08-2.78)$ & 0.02 \\
\hline SOFA score on ICU admission & 124 & $1.09(1.01-1.16)$ & 0.02 \\
\hline APACHE I| score on ICU admission & 124 & $1.03(1.00-1.06)$ & 0.037 \\
\hline \multicolumn{4}{|l|}{ Situation on the 21st day of MV } \\
\hline No tracheostomy & 31 & $2.67(1.70-4.17)$ & $<0.001$ \\
\hline Consciousness (GCS = 15) & 74 & $0.79(0.52-1.20)$ & 0.27 \\
\hline MDR/XDR bacterial infection & 63 & $1.53(1.02-2.32)$ & 0.042 \\
\hline Intolerance of enteral nutrition ${ }^{d}$ & 43 & $1.90(1.25-2.90)$ & $<0.01$ \\
\hline Platelet $\leq 150 \times 10^{9} / \mathrm{L}$ & 49 & $1.97(1.30-2.97)$ & $<0.01$ \\
\hline On vasopressors & 41 & $1.70(1.11-2.61)$ & 0.02 \\
\hline On renal replacement therapy & 24 & $1.59(0.97-2.61)$ & 0.068 \\
\hline
\end{tabular}

$\mathrm{HR}$, hazard ratio. Cl, confidence interval. NYHA, the New York Heart Association. ICU, intensive care unit. SOFA, sequential organ failure assessment. APACHE, acute physiology and chronic health enquiry. MV, mechanical ventilation. GCS, Glasgow coma scale. MDR, multi-drug-resistant. XDR, Extensively drug-resistant

${ }^{\mathrm{a}}$ Factors with number of events $>10$ were included. ${ }^{\mathrm{b}}$ Smoking of more than 10 cigarettes per day for more than 1 year, including current or previous smokers. ${ }^{c}$ Included neurosurgery, thyroid surgery, and orthopedic surgery. ${ }^{d}$ Included total parenteral and combined enteral-parenteral nutrition

contents/37/69715.html), people older than 60 years will be about 248 million by 2020 (17\% of the present population in China). Along with an aging population is the progression in medical technology and therapeutic theory, the number of PMV patients will also be increasing in China with time. Thus, it is of great clinical significance to evaluate the prognosis of PMV patients in ICUs.

Our results showed that, for patients requiring PMV after surgery, cancer surgery, together with no tracheostomy, enteral nutrition intolerance, platelet count $\leq 150 \times 10^{9} / \mathrm{L}$, use of vasopressors and renal replacement therapy on the 21st day of MV was associated with shortened 1-year survival. Since it is a retrospective study, it is impossible to know whether the factors associated with mortality are markers of severity or determinants of death.

A study showed that low platelet count, use of vasopressors, and requirement of renal replacement therapy on day 21 of $\mathrm{MV}$ are predictors of 1-year mortality in PMV patients in a mixed ICU in the United States [14], which is similar to our finding. The same study showed that age was a predictor of 1-year mortality in PMV patients, but this was not demonstrated in our study; this might have been caused by the different study populations. In critically ill patients, thrombocytopenia is usually caused by severe infections, side effect of medications, and myelosuppression among others; which is regarded as a sign of illness aggravation [15]. Requirement of vasopressors implies an unstable circulation, which is associated with higher occurrence of multiple organ dysfunction syndrome (MODS) [16]. In patients with sepsis and MODS, requirement of vasopressors is also associated with increased 1-year and 5-year mortality [17]. Requirement of renal replacement therapy on the 21st day of MV is usually caused by renal failure, and is also regarded as a sign of poor prognosis [12].

A study showed that the overall 1-year survival rate in PMV cancer patients was $14.3 \%$ [13], which was poorer generally, than that in patients with other comorbidities [18]. After cancer surgery, PMV patients showed poor prognosis, which could be attributed to the cancer itself as well as the development of cancer recurrence/metastasis after surgery $[19,20]$.

In a study involving 429 patients which evaluated hospital and long-term outcome after tracheostomy for respiratory failure, the results showed that those who were weaned off $\mathrm{MV}$ and placed on tracheostomy tubes had lower 3-year mortality than ventilator-dependent patients $(P<0.001)[21]$. In the present study, the patients not inserting tracheostomy might often meant with high risk of death, and have increased the use of sedatives and opioids, maybe dependence on MV ultimately, which was associated with prolonged 1-year mortality.

Critically ill patients on MV are at risk of underfeeding and progressive malnutrition, and this population often receives less than the required energy and protein [22]. Enteral nutrition (EN) is preferred over parenteral nutrition (PN) because it is more physiological and less likely to result in hepatobiliary dysfunction and electrolyte imbalance [23]. In addition, when compared with EN, use of $\mathrm{PN}$ has been linked to higher incidence of infection, 
Table 4 Predictors of 1-year survival (multivariate Cox Proportional Hazard analyses)

\begin{tabular}{|c|c|c|c|}
\hline \multirow[t]{2}{*}{ Predictors } & \multirow{2}{*}{$\begin{array}{l}\text { Univariate analysis } \\
P \text { value }\end{array}$} & \multicolumn{2}{|l|}{$\begin{array}{l}\text { Multivariate } \\
\text { Analysis }^{a}\end{array}$} \\
\hline & & HR $(95 \% \mathrm{Cl})$ & $P$ value \\
\hline Cancer diagnosis & 0.083 & $2.14(1.37-3.35)$ & $<0.01$ \\
\hline Intra-thoracic/abdominal surgery (vs. others) ${ }^{\text {b }}$ & 0.023 & - & - \\
\hline SOFA score on ICU admission ${ }^{c}$ & 0.019 & - & - \\
\hline APACHE II score on ICU admission & 0.037 & - & - \\
\hline No tracheostomy on day 21 of MV & $<0.001$ & $2.01(1.22-3.30)$ & $<0.01$ \\
\hline MDR/XDR bacterial infection on day 21 of MV & 0.042 & - & - \\
\hline Intolerance of enteral nutrition on day 21 of $\mathrm{MV}^{\mathrm{d}}$ & 0.003 & $1.88(1.19-2.97)$ & 0.01 \\
\hline Platelet $\leq 150 \times 10^{9} / \mathrm{L}$ on day 21 of $\mathrm{MV}$ & 0.001 & $1.77(1.14-2.75)$ & 0.01 \\
\hline On vasopressors on day 21 of MV & 0.015 & $1.74(1.11-2.74)$ & 0.02 \\
\hline On renal replacement therapy on day 21 of MV & 0.068 & $1.71(1.01-2.91)$ & 0.047 \\
\hline
\end{tabular}

$\mathrm{HR}$, hazard ratio. $\mathrm{Cl}$, confidence interval. ICU, intensive care unit. SOFA, sequential organ failure assessment. APACHE, acute physiology and chronic health evaluation. MV, mechanical ventilation. MDR, multi-drug-resistant. XDR, Extensively drug-resistant

${ }^{a}$ Factors with $\mathrm{P}<0.10$ and number of outcomes $>10$ were included in the multivariate model (Backward). ${ }^{\mathrm{b}}$ Included neurosurgery, thyroid surgery, and orthopedic surgery. ${ }^{c}$ Not included because of collinearity with APACHE II score. ${ }^{d}$ Included total parenteral and combined enteral-parenteral nutrition

impaired wound healing, and gastrointestinal bleeding [24].

The multivariate Cox proportional model can be used as a prognostic assessment tool for critically ill patients after surgery in the future. Clinicians should not only pay attention to platelet count, use of vasopressors, and the need for renal replacement on the 21st day of MV in patients, but also to assess whether patients have malignant tumors, need tracheostomy, and enteral nutritional support.

The area under curve for the combination of our multivariate factors was more than the area for the ProVent score. There was significant difference between the
ProVent score and the combination of our multivariate factors in predicting 1-year survival using ROC curves, however, the sample size was relatively small and the comparison might be unconvincing.

This study had major limitations. First, the sample size was relatively small. Patients requiring PMV after surgery had a small sample size, with a percentage of only $0.5 \%$ in our study. A larger sample size is needed to develop a more accurate predictive model. Secondly, our study retrospectively analyzed patients' data over a long period. Clinical practice and, thus, patient characteristics might have changed during that period, which made it lack of validation.

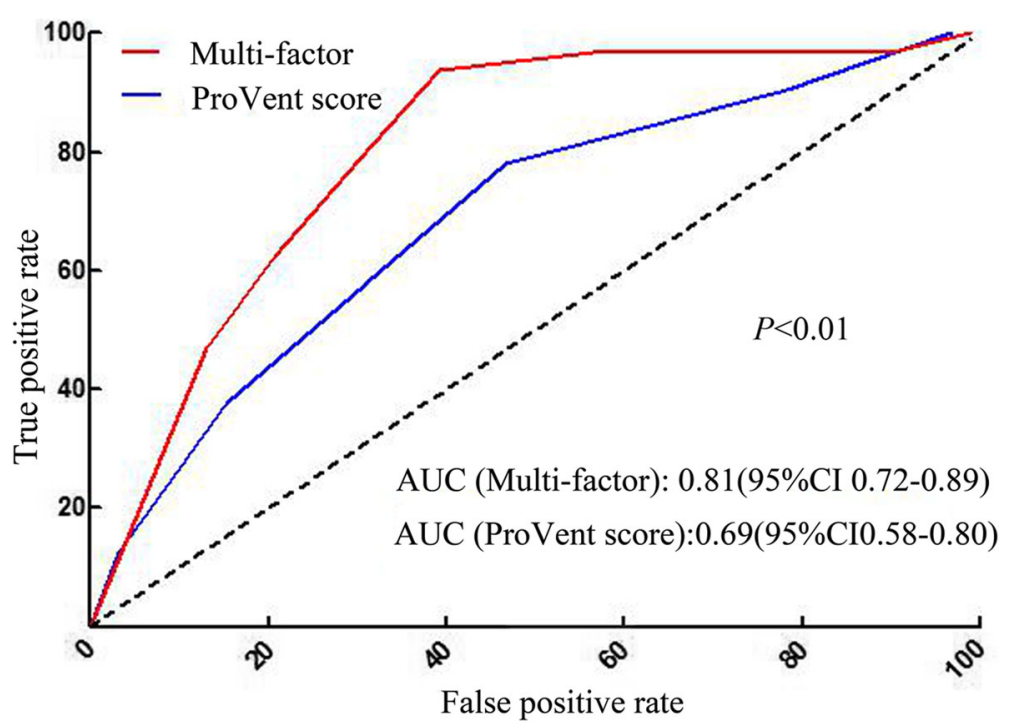

Fig. 2 Comparison between the combination of multivariate factors and the ProVent Score in predicting 1-year mortality 


\section{Conclusions}

For patients requiring PMV after surgery, cancer diagnosis, no tracheostomy, enteral nutrition intolerance, low platelet count, and dependence on vasopressors and renal replacement therapy on the 21st day of MV were associated with worse 1-year survival. The prognosis in PMV patients in ICUs can facilitate the decision that making process of the physicians and patients' family members on treatment schedule.

\section{Abbreviations}

APACHE: acute physiology and chronic health evaluation; Cl: confidence interval; COPD: chronic obstructive pulmonary diseases; GCS: Glasgow coma scale; HR: hazard ratio; ICU: intensive care unit; MDR: multi-drug-resistant; MV: mechanical ventilation; NYHA: the New York Heart Association; POCs: postoperative complications; SOFA: sequential organ failure assessment; XDR: Extensively drug-resistant

\section{Acknowledgements}

The authors wish to acknowledge all the authors who performed the studies included in this work.

\section{Authors' contributions}

YMS and SLL contributed to data interpretation, drafting of the manuscript and critical revision of the manuscript. SPW, CL, GL, JXX, HZW, FL, GQY, ZGC and YLL contributed to data collection and data interpretation. MXS contributed to data interpretation and performed statistical analysis. DXW contributed to interpretation and critical revision of the manuscript. SLL and DXW chaired the group, conceived and designed the study, performed statistical analysis and contributed to data collection, data interpretation and critical revision of the manuscript. All authors reviewed the manuscript. All authors read and approved the final manuscript

\section{Funding}

The study is supported by Clinical Research Foundation of Peking University First Hospital (Beijing, China, 4801018).

\section{Availability of data and materials}

The datasets generated and/or analysed during the current study are not publicly available due to when individual privacy could be compromised but are available from the corresponding author on reasonable request.

\section{Ethics approval and consent to participate}

The study protocol was approved by the Ethics Committee of Peking University First Hospital (2017[1422]). As the study was pure observationa and retrospective in nature, the Ethics Committee agreed to exempt the written informed consent. However, all enrolled patients or their family members had verbally agreed to participate in the long-term follow-up before collecting data.

\section{Consent for publication}

The manuscript has been read and its submission approved by all coauthors.

\section{Competing interests}

The authors declare that they have no financial or non-financial competing of interest.

\section{Author details}

${ }^{1}$ Department of Critical Care Medicine, Peking University First Hospital, Beijing 100034, China. ${ }^{2}$ Department of Critical Care Medicine, China-Japan Friendship Hospital, Beijing 100029, China. ${ }^{3}$ Department of Critical Care Medicine, Beijing Cancer Hospital, Beijing 100142, China. ${ }^{4}$ Department of Critical Care Medicine, Peking University Third Hospital, Beijing 100191, China. ${ }^{5}$ Department of Critical Care Medicine, National Center of Gerontology, Beijing Hospital, Beijing 100730, China. ${ }^{6}$ Department of Biostatistics, Peking University First Hospital, Beijing 100034, China.
Received: 10 October 2019 Accepted: 16 January 2020

Published online: 21 February 2020

\section{References}

1. Maclntyre NR, Epstein SK, Carson S, et al: National Association for Medical Direction of Respiratory Care. Management of patients requiring prolonged mechanical ventilation: report of a NAMDRC consensus conference. Chest 2005; 128:3937-3954.

2. Kahn JM, Le T, Angus DC, et al: ProVent Study Group Investigators. The epidemiology of chronic critical illness in the United States. Crit Care Med 2015: 43:282-287. https://doi.org/10.1097/CCM.0000000000000710.

3. Halpern NA, Pastores SM, Greenstein RJ. Critical care medicine in the United States 1985-2000: an analysis of bed numbers, use, and costs. Crit Care Med. 2004;32:1254-9.

4. McGee WT. Expectations and outcomes of prolonged mechanical ventilation. Crit Care Med. 2010;38:1393-4. https://doi.org/10.1097/CCM. Ob013e3181d53b73.

5. Cox CE, Carson SS, Lindquist JH, et al. Quality of life after mechanical ventilation in the aged (QOL-MV) investigators. Differences in one-year health outcomes and resource utilization by definition of prolonged mechanical ventilation: a prospective cohort study. Crit Care. 2007;11:R9.

6. Dowdy DW, Eid MP, Sedrakyan A, et al. Quality of life in adult survivors of critical illness: a systematic review of the literature. Intensive Care Med. 2005:31:611-20.

7. Azoulay E, Pochard F, Kentish-Barnes N, et al. Risk of post-traumatic stress symptoms in family members of intensive care unit patients. Am J Respir Crit Care Med. 2005;171:987-94.

8. Flaatten H. Mental and physical disorders after ICU discharge. Curr Opin Crit Care. 2010;16:510-5. https://doi.org/10.1097/MCC.0b013e32833cc90b.

9. de Miranda S, Pochard F, Chaize M, et al. Postintensive care unit psychological burden in patients with chronic obstructive pulmonary disease and informal caregivers: a multicenter study. Crit Care Med. 2011;39: 112-8. https://doi.org/10.1097/CCM.0b013e3181feb824.

10. Carson SS, Kahn JM, Hough CL, et al. A multicenter mortality prediction model for patients receiving prolonged mechanical ventilation. Crit Care Med. 2012;40:1171-6. https://doi.org/10.1097/ CCM.0b013e3182387d43.

11. Mok JH, Kim YH, Jeong ES, et al. Clinical application of the ProVent score in Korean patients requiring prolonged mechanical ventilation: a 10-year experience in a university-affiliated tertiary hospital. J Crit Care. 2016;33:15862. https://doi.org/10.1016/j.jcrc.2016.02.017.

12. Leroy $G$, Devos $P$, Lambiotte $F$, et al. One-year mortality in patients requiring prolonged mechanical ventilation: multicenter evaluation of the ProVent score. Crit Care. 2014;18:R155. https://doi.org/10.1186/cc13994.

13. Hung MC, Lu HM, Chen $L$, et al. Life expectancies and incidence rates of patients under prolonged mechanical ventilation: a population-based study during 1998 to 2007 in Taiwan. Crit Care. 2011;15:R107. https://doi.org/10. $1186 /$ cc10128.

14. Carson SS, Garrett J, Hanson LC, et al. A prognostic model for one-year mortality in patients requiring prolonged mechanical ventilation. Crit Care Med. 2008;36:2061-9. https://doi.org/10.1097/CCM.0b013e31817b8925.

15. Ogura H, Gando S, Iba T, et al. SIRS-associated coagulopathy and organ dysfunction in critically ill patients with thrombocytopenia. Shock. 2007;28: 411-7. https://doi.org/10.1097/shk.0b013e31804f7844.

16. Russell JA, Lee T, Singer J, et al. Days alive and free as an alternative to a mortality outcome in pivotal vasopressor and septic shock trials. J Crit Care. 2018;47:333-7. https://doi.org/10.1016/j.jcrc.2018.05.003.

17. Linder A, Lee T, Fisher J, et al: Short-term organ dysfunction is associated with long-term (10-Yr) mortality of septic shock. Crit Care Med 2016; 44: e728- e736. https://doi.org/10.1097/CCM.0000000000001843.

18. Shih CY, Hung MC, Lu HM, et al. Incidence, life expectancy and prognostic factors in cancer patients under prolonged mechanical ventilation: a nationwide analysis of 5,138 cases during 1998-2007. Crit Care. 2013;17:R144. https://doi.org/10.1186/cc12823.

19. Siegel RL, Miller KD, Jemal A. Cancer statistics, 2017. CA Cancer J Clin. 2017; 67:7-30. https://doi.org/10.3322/caac.21387.

20. Poon RT, Fan ST, Wong J. Clinical implications of circulating angiogenic factors in cancer patients. J Clin Oncol. 2001;19:1207-25.

21. Engoren M, Arslanian-Engoren C, Fenn-Buderer N. Hospital and long-term outcome after tracheostomy for respiratory failure. Chest. 2004;125:220-7. 
22. Kyle UG, Genton L, Heidegger CP, et al. Hospitalized mechanically ventilated patients are at higher risk of enteral underfeeding than non-ventilated patients. Clin Nutr. 2006;25:727-35.

23. Barr J, Hecht M, Flavin KE, et al. Outcomes in critically ill patients before and after the implementation of an evidence-based nutritional management protocol. Chest. 2004;125:1446-57.

24. Rice TW, Swope T, Bozeman S, et al. Variation in enteral nutrition delivery in mechanically ventilated patients. Nutrition. 2005;21:786-92.

\section{Publisher's Note}

Springer Nature remains neutral with regard to jurisdictional claims in published maps and institutional affiliations.

Ready to submit your research? Choose BMC and benefit from:

- fast, convenient online submission

- thorough peer review by experienced researchers in your field

- rapid publication on acceptance

- support for research data, including large and complex data types

- gold Open Access which fosters wider collaboration and increased citations

- maximum visibility for your research: over $100 \mathrm{M}$ website views per year

At BMC, research is always in progress.

Learn more biomedcentral.com/submissions 